\title{
Management of allergic problems in primary care: time for a rethink?
}

\author{
Dermot Ryan $^{a}$, Mark Levy ${ }^{b}$, Adrian Morris ${ }^{c}$, Aziz Sheikh ${ }^{d}$, \\ Samantha Walker ${ }^{e, *}$
}

\author{
a Department of General Practice and Primary Care, University of Aberdeen, Westburn Road, \\ Aberdeen AB25 2AY, UK \\ ${ }^{\mathrm{b}}$ Division of Community Health Sciences: GP Section, University of Edinburgh, c/o Smithy House, \\ Waterbeck, Lockerbie DG11 3EY, UK \\ ${ }^{c}$ Allergy Clinic, Royal Brompton Hospital, London UK \\ ${ }^{\mathrm{d}}$ Division of Community Health Sciences: GP Section, University of Edinburgh, UK

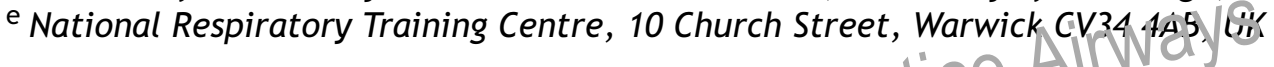 \\ Received 8 November 2004; accepted 3 January 2505
}

KEYWORDS
Allergy;
Primary care;
Management

\footnotetext{
* Corresponding author. Tel.: +44 1926 838975; fax: +44 1926493224.
}

E-mail address: s.walker@nrtc.org.uk (S. Walker). 
training for those wishing to manage successfully more difficult allergy cases and allergy diagnosis.

๑ 2005 General Practice Airways Group. Published by Elsevier Ltd. All rights reserved.

\section{Background}

Allergic diseases affect around $20 \%$ of the United Kingdom population [1], including $30-40 \%$ of children [2], and hospital admissions for severe allergic disease have increased tenfold in the last 10 years [3-5]. The majority of patients experience only mild or moderate symptoms and can be successfully managed in primary care with conventional pharmacotherapy without the need for confirmation of an allergic mechanism or identification of specific allergic triggers. However, a large proportion remain undiagnosed [6]. More troublesome, drug-resistant or life-threatening symptoms warrant specialist assessment. Ideally, this would be by either an allergy specialist or an organ-based specialist with an interest in allergy (e.g. ear, nose and throat surgeon, respiratory physician, dermatologist or gastroenterologist). The lack of UK National Health Service specialist allergy services, however, causes many people to seek help for allergy problems frog non medical providers, soms of wit im may provide misleading and expensive information of clubious value [7]. Anstner important 12 of concibuting to this phenomenon is increasing patient expectations for diagnostic testing, which although feasible [8], is not routinely available in primary care.

Historically, the first points of access for allergy sufferers to professional care have been the pharmacist, general practitioner (GP) or accident and emergency departments. NHS Direct and 'walk-in' centres are new and additional frontline resources which serve further to fragment care. New health-care models are constantly being introduced in an attempt to address unmet need and burgeoning demand. In order to move forward, minimum standards of care need to be developed and clear management pathways established.

In order to improve provision for, and access to, National Health Service allergy services, a novel all-embracing strategy is required. We propose the development of specialist community allergy services, identifying potential for expanded roles for pharmacists, doctors and nurses $[9,10]$. Underpinning this model is a recognition of the importance of self-care and patient expertise as essential contributors to successful chronic disease management. This concept has been utilised in chronic disease education programmes initially in the USA [11] and more recently in the UK in the form of the expanding 'Expert Patient Programme' (EPP) which aims to ameliorate the burden posed for patients with chronic diseases by improving coping skills [12].

\section{Morbidity and mortality}

Allergy is a systemic disease manifesting as chronic symptoms in multiple organ systems. Although severe reactions are rare, untreated mild or moderate symptoms can be disruptive. Nasal symptoms can cause sleep disruption and poor concentration [13], a particular problem in children whose exams may be disrupted by hayfever at the height of the pollen season. In a study of patients with perennial rhinitis, $8 \%$ reported being 'moderately' or 'severely' troubled by their rhinitis symptoms [14]. Chronic Irtifarie anid eczema can disrupt sleep calde trict or impair daily activities [15.10- whilst unconfirmed 'allergy' to foods or antibiotics cart ead to unnecessary avoidance and su'D-Dotimalnutrition or costly treatment [17-20]. Recognition of allergy symptoms can be helpful in identifying patients at risk of more severe symptoms; a suspicion of food allergy in patients with asthma, for example, should prompt specialist referral as these patients are at an increased risk of fatal anaphylaxis [21-24]. Recognition of symptoms and consensus- or evidence-based treatment will be effective in the majority of patients and provides patient and professional satisfaction. Currently, evidence suggests that GPs are inexperienced in allergy management [25], but also have little interest in improving it, the lack of prioritisation of most allergic disorders in the new GP contract serving as another additional barrier to enhancing quality of care. This clearly needs to be addressed before allergy management can improve.

\section{Management of allergy}

Management of the most common allergic diseases is generally not allergen-specific and relies in the main on pharmacotherapy. Although asthma [26] and rhinitis [27] guidelines are underpinned by aeroallergen avoidance [28] there is, as yet, insufficient evidence of the feasibility, effectiveness and cost-effectiveness of avoidance 
measures [29-32] in order to convince those working in primary care that routine performance of objective diagnostic tests which underpin allergen avoidance advice (skin prick tests/specificIgE tests) is worthwhile. For the majority, identification of a specific allergic trigger is not necessary as long as symptoms respond to pharmacotherapy; in cases that do not, identification and avoidance of allergens may offer some benefit.

Despite these reservations, guidelines are now available for the management of asthma [26], conjunctivitis [33], rhinitis [27,34], eczema [35], urticaria, food allergy [36] and anaphylaxis [37] which could be used in general practice to improve and standardise care. It is clear that levels of interest in allergy differ, but it is important that patients receive at least effective pharmacotherapy. Here we examine current practice at each level of service and offer suggestions for further development. Further details are shown in Table 1.

\section{Tiers of care and training needs: the way forward}

\section{Self care}

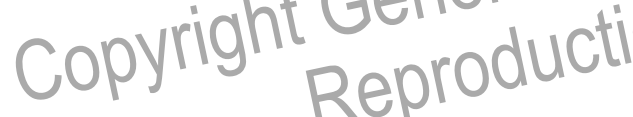

Self-care describes how people who believe they have an illness attempt to help themselves before they access formal healthcare. This is not to be confused with self-management which is what the health-care system should empower patients to do after formal assessment.

Allergy receives constant media attention and self-care is common; patients rely on advice from friends and family, the internet, magazines and newspapers, but rarely access reliable sources of information. There is widespread confusion amongst the public about what is and what is not allergy, fuelled by a flourishing 'alternative' allergy industry, which often provides unvalidated tests and recommends unnecessary avoidance regimens or expensive treatments. The internet is unregulated, and so provides comprehensive, if often inaccurate, information on allergies and their management. Patients may not consult their GP or practice nurse (PN) because of a perceived lack of interest in their symptoms; this lack of interest was confirmed recently in a study of the attitudes of GPs to allergy [25]. In another UK study, $82 \%$ of GPs judged NHS care for people with allergy to be of poor quality [38].
We need to understand and define patients' needs, as well as to inform the public about allergic disease. In particular, people need to know how to recognise serious or life-threatening manifestations without creating alarm. Patients and their carers are keen to identify triggers in order that they may avoid them. They do not share our professional standards of evidence-based advice and would often rather attempt avoidance or natural remedies than resort to pharmacotherapy.

One approach in the UK may be to use existing organisations (e.g. British Society for Allergy \& Clinical Immunology, General Practice Airways Group, British Thoracic Society) to vet internet sites and to become involved in assessing the accuracy and usefulness of published information [10]. Such a strategy could facilitate self-help in a manner that reflects evidence-based guidelines.

\section{Pharmacy care}

The pharmacist is often patients' first point of contact with the healthcare system. Currently, most pharmacists provide apo opliale advice and over-the-counter mediftion, but there is the potercie or an expanded role. Training in cecugnising alle gir jymptoms, practical advice on aypiajig|trigger factors, and instruction on how to optimise effective delivery of nasal corticosteroids, cromones and antihistamines, would enable pharmacists to offer an improved service to patients and may reduce the need for primary care consultations. This development would be in line with recent UK government policy [39]. This activity could be funded by the NHS centrally with training provided through accredited allergy courses.

\section{Primary care}

Most allergic disease is managed within primary care, although few GPs have had any formal allergy training during undergraduate or postgraduate training. Recent data demonstrates much room for self-rated improvement in clinical competence $[25,40]$. GPs' interest in allergy is low, yet they feel that diagnosis and management is straightforward and that access to secondary care is poor [25]. In contrast, practice nurses have been shown to be interested in improving their knowledge of allergy and expanding their role [25] but they experience barriers such as lack of time, support, and other resources, as well as competing priorities (e.g. United Kingdom National Service Frameworks which prioritise work in clinical areas). 
Table 1 Proposed levels of care in schematic form together with training requirements.

\begin{tabular}{|c|c|c|c|}
\hline Person & Services provided & Skills required & Information/training required \\
\hline Patient & - Self care & $\begin{array}{l}\text { - Symptom-specific } \\
\text { self-management } \\
\text { - Symptom control } \\
\text { - Medicines self-management }\end{array}$ & $\begin{array}{l}\text { - Disease-specific information } \\
\text { - Reputable educational resources } \\
\text { - Availability of OTC medication } \\
\text { - Drug-specific information } \\
\text { - When to seek help and where from }\end{array}$ \\
\hline Pharmacist & $\begin{array}{l}\text { - OTC medication } \\
\text { - Disease management } \\
\text { - Referral }\end{array}$ & $\begin{array}{l}\text { - Symptom-specific management } \\
\text { - How to treat allergy with OTC } \\
\text { medications }\end{array}$ & $\begin{array}{l}\text { - Common allergic symptoms and their } \\
\text { presentation } \\
\text { - Pharmacological management of allergic } \\
\text { disease } \\
\text { (c) device technique (eg nasal sprays, eye } \\
\text { drops) } \\
\text { - Knowledge of local NHS allergy services: } \\
\text { when and where to refer }\end{array}$ \\
\hline $\begin{array}{l}\text { GP/PN (minimum service to be } \\
\text { provided in primary care by GP/PNs } \\
\text { with no specialist allergy interest) }\end{array}$ & $\begin{array}{l}\text { - Allergy symitcmel } \\
\text { manalgerignt } \\
\text { - Reierral Rep }\end{array}$ & $\begin{array}{l}\text { - Symptompanarint } \\
\text { - Optimal symptom control using } \\
\text { POM drugs } \\
\text { - Recognition of severe disease }\end{array}$ & $\begin{array}{l}\text { - Common allergic conditions and their } \\
\text { manifestations in multiple organ systems } \\
\text { - Simple algorithms on disease management } \\
\text { - Availability of diagnostic tests } \\
\text { - Local availability of NHS allergy services: } \\
\text { when and where to refer }\end{array}$ \\
\hline $\begin{array}{l}\text { Practice lead in allergy (GP/PN } \\
\text { with an allergy interest but with } \\
\text { no access to increased consultation } \\
\text { time or basic diagnostic tests) }\end{array}$ & $\begin{array}{l}\text { - Allergy diagnosis } \\
\text { - Allergy symptom } \\
\text { management } \\
\text { - Referral }\end{array}$ & $\begin{array}{l}\text { - History taking } \\
\text { - Disease management } \\
\text { - Optimal symptom control using } \\
\text { POM drugs }\end{array}$ & $\begin{array}{l}\text { Diploma/degree } \\
\text { - Epidemiology of allergic disease } \\
\text { - Genetic influences } \\
\text { - Environmental influences Resources } \\
\text { - Current guidelines on disease diagnosis and } \\
\text { management } \\
\text { - Local availability of NHS allergy services: } \\
\text { when and where to refer }\end{array}$ \\
\hline
\end{tabular}


Table 1 (Continued)

\begin{tabular}{|c|c|c|c|}
\hline Person & Services provided & Skills required & Information/training required \\
\hline $\begin{array}{l}\text { GP/PN with a special interest in } \\
\text { allergy (GP/PN with allergy } \\
\text { training with access to increased } \\
\text { consultation time and basic } \\
\text { diagnostic tests) }\end{array}$ & $\begin{array}{l}\text { - Allergy diagnosis } \\
\text { - Allergy symptom } \\
\text { management } \\
\text { - Simple allergy testing } \\
\text { - Referral }\end{array}$ & $\begin{array}{l}\text { - History takno and } \\
\text { in : Erp } € \text { tation } \\
\text { - Performance of simple } \\
\text { diagnostic tests } \\
\text { - Interpretation of simple } \\
\text { diagnostic tests } \\
\text { - Organ-specific allergy } \\
\text { investigations } \\
\text { - Optimal symptom } \\
\text { control using POM drugs }\end{array}$ & $\begin{array}{l}\text { Degree/diploma } \\
\text { - As for practice lead + } \\
\text { - How to perform and interpret diagnostic } \\
\text { tests } \\
\text { - Allergy and non-allergy: symptoms and } \\
\text { management } \\
\text { Resources } \\
\text { - As for practice lead + } \\
\text { - Evidence-based decision-making based on } \\
\text { current guidelines on disease diagnosis and } \\
\text { manerienent } \\
\text { Mentorship from allergy specialist } \\
\text { Membership of appropriate professional body } \\
\text { - Epidemiology of allergic disease } \\
\text { - Genetic influences } \\
\text { - Environmental influences } \\
\text { - Recognition of allergy co-morbidity } \\
\text { - How to perform and interpret diagnostic } \\
\text { tests } \\
\text { - How to perform and interpret organ- } \\
\text { specific allergy investigations } \\
\text { - Allergy and non-allergy: symptoms and } \\
\text { current guidelines on disease diagnosis and } \\
\text { management } \\
\text { - Local availability of NHS allergy services: } \\
\text { when and where to refer }\end{array}$ \\
\hline
\end{tabular}




\begin{tabular}{|c|c|c|c|}
\hline Person & Services provided & Skills required & Information/training required \\
\hline $\begin{array}{l}\text { Consultant allergist (with specialist } \\
\text { nurse and dietician) }\end{array}$ & $\begin{array}{l}\text { - Allergy diagnosis } \\
\text { - Management of complex allergic } \\
\text { and pseudo-allergic symptoms } \\
\text { - Dietetic advice }\end{array}$ & $\begin{array}{l}\text { - Detailed history taking } \\
\text { and interpretation } \\
\text { - Performance of simple } \\
\text { and complex diagnostic } \\
\text { tests } \\
\text { - Interpretation of simple } \\
\text { and complex diagnostic } \\
\text { tests } \\
\text { - Immunotherapy }\end{array}$ & $\begin{array}{l}\text { - Epidemiology of allergic disease } \\
\text { - Genetic influences } \\
\text { - Environmental influences } \\
\text { - How to perform and interpret diagnostic } \\
\text { sens/ (e.g. testing for food/drug/venom } \\
\text { tests, bronchial provocation tests) } \\
\text { - Allergy and non-allergy: symptoms, } \\
\text { management and further referral } \\
\text { - Evidence-based decision-making based on } \\
\text { current guidelines on disease diagnosis and } \\
\text { management } \\
\text { - Knowledge of recent developments in the } \\
\text { diagnosis and management of allergic and } \\
\text { pseudo-allergic diseases }\end{array}$ \\
\hline
\end{tabular}


Improved access to allergy training is an essential prerequisite to improving delivery of allergy services in primary care. There is evidence that such training improves patient outcomes [41]. Furthermore, Primary Care Trusts (PCTs) need to be made aware of the burden of allergic disease and alerted to their responsibilities to provide the resources to meet these needs $[42,43]$.

\section{Intermediate care}

This would be a new area of service. It should not be considered as a cheap option to expanding a high level allergy service but rather should be seen as an integral part of the overall strategy. A Practitioner with a Special Interest (PwSI), allergy nurse practitioner, or organ-based specialist could manage the more complex problems encountered by GPs.

The UK Government has pledged to have 1000 PwSIs in post by 2004 [44]. Although there is at present no commitment to PwSIs in allergy,

Box 1 Role of practitioners with special interest in allergy

- Management of more challengirg problems:

- Nasal symptorlol unresponsive combination iherapy

- Skin symptoms

- Food allergy and atypical symptoms attributed to food

- Drug reactions

- Generalised insect venom reactions

- Asthma when an allergic trigger is suspected

- Anaphylaxis

- Advice

- Primary care practitioners

- Primary care organisations and other public bodies.

- Access

- Allergy testing (skin prick testing/slgE)

- Imaging

- Allergen injection immunotherapy

- Specialist expertise.

- Education

- Liaison

- Researchers, Public health leads

Clinical governance

Schools and school nurses

- Patient organisations there is support both from the Royal College of Physicians [43] and the UK parliamentary allergy health committee [45]. Their roles, support and training needs are outlined in Box 1 and Table 1.

Since allergy services in the UK are so limited, additional funding and investment will be necessary. A key requirement for success will inevitably be obtaining commitment and funding by Primary Care Organisations (PCOs). Successful models already exist in some PCTs for GPs with a special interest (GPwSIs) in ENT, dermatology and sports medicine, and the General Practice Airways Group (GPIAG) has proposed models for the accreditation [46], appraisal of, and developmental support for [47] GPwSIs in respiratory medicine, all of which can be referred to when establishing PwSls in allergy.

\section{Secondary care}

The majority of secondary care referrals are made to organ-based specialists sych as ENT surgeons, chest physicians and dermatologists. Allergy trailing in toese disciplines is variable and t'ie de Gorten little access to diagnostic tests. rable 1 outinas the level of service which may be EXdeced in secondary care by those purporting to provide an allergy service. There is a need for organ-based specialists to recognise the systemic nature of allergic disease in order to reduce the number of individual referrals for organ-specific allergic symptoms.

\section{Tertiary care}

Although a discussion of the possible structure of reconfigured secondary and tertiary care services falls beyond the scope of this paper, it is important to note that services are geographically patchy and are, for most patients, difficult to access at present. Planned expansion to a reasonable level may take many years [48]. Nevertheless, patients with severe, drug resistant or life-threatening disease require expert allergy assessment and attempts to refer patients should be made where possible. Other reasons for referral should include food allergy, drug allergy, occupational allergy, complex or severe cross reactivity, or cases of diagnostic uncertainty. Allergy specialists would have access to the full range of diagnostic and therapeutic facilities including other specialist team members such as specialist nurses, dieticians and psychologists. 


\section{Conclusions}

Allergy services in the UK are inadequate, but the majority of patients can be successfully treated in the community with appropriate training. The principles underlying improved allergy management are: increased awareness of allergy; improved education and training of health-care providers; improved access to reliable information; and acquisition of the resources necessary to deliver the services.

Information concerning the nature of allergy and the avenues available for its management should be readily available to the public. Although there is an increasing interest in allergy, patients cannot be expected to be able to differentiate between reliable information and marketing opportunities. The British Society for Allergy and Clinical Immunology is currently investigating the provision of simple information and advice to patients including links to reputable websites peer-reviewed by a member of the Society.

Improved knowledge of allergy and training in the management of allergic disease is recommended to improve care. Levels of interest in allergy training among pharmacists requires investigation, although anecdotal evidenice suggests that pharmacists are keeneti arclude allergy advice as part of hrieic te in dispensing

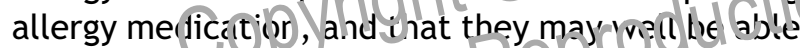
to provide a more accessible a iegy advice service in the future. Allergy training for the primary care team is necessary to enable them to improve their care for the majority of patients and to equip them with the skills to recognise when to refer patients. There is also the possibility of creating PwSIs in allergy together with support teams. This should enable most patients with allergy to be managed efficiently and locally. Initiatives to expand facilities in secondary/tertiary care may be more successful if they are driven by primary care demand which is itself responsive to patient demand.

\section{Conflicts of interest}

Dermot Ryan has been sponsored to attend major symposia by, received consultancy fees and speaker fees from, and arranged educational activities for $3 \mathrm{M}$ Pharmaceuticals, Astra Zeneca, GlaxoSmithKline, Schering-Plough, MSD and Novartis Pharma.

Adrian Morris has been an advisor for Sweden Diagnostics (Pharmacia) and UCB Institute of Allergy.
Mark Levy has been sponsored to attend international conferences, and has accepted consultancy fees and speaker fees for participating in educational activities for, Altana Pharmaceuticals, Astra Zeneca, Cheisi-Trinity, GlaxoSmithKline, Innovata Biomedica, MSD, Novartis Pharma, Schering-Plough, and Sweden Diagnostics (Pharmacia).

Aziz Sheikh has received reimbursement for lectures and meetings from Schering-Plough Ltd., UCB Pharma, Aventis, Pfizer Ltd., GlaxoSmithKline.

Samantha Walker has received honoraria for consultancy, lectures and publications from GlaxoSmithKline, UCB, Pharmacia UK, Schering Plough UK, Novartis, Aventis and Pfizer UK.

\section{References}

[1] Strachan DP, Sibbald B, Weiland SK, Ait-Khaled N, Anabwani $\mathrm{G}$, Anderson HR, et al. Worldwide variations in prevalence of symptoms of allergic rhinoconjunctivitis in children: the International Study of Asthma and Allergies in Childhood (ISAAC). Pediatr Allergy Immunol 1997;8: 161-76.

[2] Strachan DP. Epidemiology of hayfever: towards a community diagnosis. Clin Exp fitergy 1995;25:296-303.

[3] Sheikh A, Alves E. SHcsotal admissions for acute anaphylexis: Winc trend study. Br Med J 2000;320:1441.

41 Gupta R, Sheikh A, Strachan DP, Anderson HR. Increasing hospital adpissions for systemic allergic disorders in Frgtand: arialysis of national admissions data. $\mathrm{Br}$ Med $\mathrm{J}$ 2003;327:1142-3.

[5] Gupta R, Sheikh A, Strachan DP, Anderson HR. The estimated cost of allergic disorders to the NHS is over £1billion/annum. Clin Exp Allergy 2004;34:520-6.

[6] Bauchau V, Durham SR. Prevalence and rate of allergic rhinitis in Europe. Eur Resp J 2004;24:758-64.

[7] Allergy Testing. Which? 1998.

[8] Sibbald B, Barnes G, Durham SR. Skin prick testing in general practice: a pilot study. J Adv Nurs 1997;26:537-42.

[9] Department of Health. Guidelines for the appointment of general practitioners with special interests in the delivery of clinical services: respiratory medicine. URL: http:// www.dh.gov.uk/PublicationsAndStatistics/Publications/ PublicationsPolicyAndGuidance/PublicationsPolicyAndGu[idanceArticle/fs/en?CONTENT_ID=4009510\&chk=VuRE9U]. 2005.

[10] Pinnock $H$, Sheikh A. Meeting the information needs of patients with allergic disorders: partnership is the key. Clin Exp Allergy 2004;34(9):1333-5.

[11] Lorig K, Ritter P, Stewart A, Sobel D, Brown BW, Bandura $A$, et al. Chronic disease and self-management program. 2 -year health status and health care utilization outcomes. Med Care 2001;39(11):1217-23.

[12] Department of Health. The expert patient: a new approach to chronic disease management for the 21st century. URL: http://www.dh.gov.uk/Publications AndStatistics/Publications/PublicationsPolicyAndGuidance/ PublicationsPolicyAndGuidanceArticle/fs/en?CONTENT_ID= 4006801\&chk=UQCoh9. 2005.

[13] Vuurman EPF, van Veggel LMA, Uiterwijk MMC, Leutner D, O'Hanlon JF. Seasonal allergic rhinitis and antihistamine effects on childrens' learning. Annals of Allergy 1993;71:121-6. 
[14] Sheikh AS, Khan-Wasti S, Fletcher M, Walker SM. Quality of life in patients with perennial rhinitis. Eur Resp J 2004;24(48):P626.

[15] O’Donnell BF, Lawlor F, Simpson J, Morgan M, Greaves M. The impact of chronic urticaria on the quality of life. $\mathrm{Br} \mathrm{J}$ Dermatol 1997;136:197-201.

[16] Linnet J, Jemec GBE. An assessment of anxiety and dermatology life quality in patients with atopic dermatitis. Br J Dermatol 1999;140:268-72.

[17] Christie C, Hine RJ, Parker JG, Burks W. Food allergies in children affect nutrient intake and growth. J American Dietary Association 2002;102(11):1648-51.

[18] Black RE, Williams SM, Jones IE, Goulding A. Children who avoid drinking cow milk have low dietary calcium intakes and poor bone health. American Journal for Clinical Nutrition 2002;76(3):675-80.

[19] Sade K, Holtzer I, Levo Y, Kivity S. The economic burden of antibiotic treatment of penicillin-allergic patients in internal medicine wards of a general tertiary care hospital. Clin Exp Allergy 2003;33(4):501-6.

[20] Primeau M-N, Kagan R, Joseph L, Lim H, Dufresne C, Duffy $C$, et al. The psychological burden of peanut allergy as perceived by adults with peanut allergy and the parents of peanut-allergic children. Clin Exp Allergy 2000;30:1135-43.

[21] Macdougall CF, Cant AJ, Colver AF. How dangerous is food allergy in childhood? The incidence of severe and fatal allergic reactions across the UK and Ireland. Arch Dis Child 2002;86:236-9.

[22] Bock SA, Munoz-Furlong A, Sampson HA. Fatalities due to anaphylactic reaction to foods. J Allergy Clin Immunol 2001;107(1):191-3.

[23] Walker S, Sheikh A. Managing anaphylaxis: effetti e emergency and long term treatment are fecesary EIIn Exp Allergy 2003;33:1015-

[24] Sheikh A, Valker S. Te 1-minute consultation food dillergy. Br Med J 2002,325:1337.

[25] Ryan D, Grant-Casey J, Scadding G, Pereira S, Pinnock $\mathrm{H}$, Sheikh A. Management of allergic rhinitis in UK primary care: baseline audit. Primary Care Resp J 2005;14(4):204-9.

[26] BTS/SIGN. British Guideline on the management of asthma. Thorax 2003; 51 (Suppl 1). http://www.sign. ac.uk/guidelines/fulltext/63/index.html, 1-94. Accessed 28.4.2005.

[27] Bousquet J, Van Cauwenberge P, Khaltaev N. Allergic Rhinitis and its Impact on Asthma. J Allergy Clin Immunol 2001;108(5):147-333.

[28] Sheikh A, Levy ML. Costs are a barrier to GPs performing skin prick testing. Br J Gen Pract 1999;49(438):67.

[29] Sheikh A, Hurwitz B. House dust mite avoidance measures for perennial allergic rhinitis: a systematic review of efficacy. Br J Gen Pract 2003;53(489):318-22.

[30] Sheikh A, Hurwitz B, Sibbald B, Barnes G, Howe M, Durham SR. House dust mite barrier bedding for childhood asthma: randomised placebo controlled trial in primary care. BMC Fam Pract 2002;3(1):12.

[31] Woodcock A, Forster L, Matthews E, Martin E, Letley L, Vickers $M$, et al. Control of exposure to mite allergen and mite-impermeable bed covers for adults with asthma. N Eng J Med 2003;349(3):225-36.
[32] Gotzsche PC, Hammarquist C, Burr M. House dust mite control measures in the management of asthma: metaanalysis. Brit Med J 1998;317:1105-10.

[33] Owen CG, Shah A, Henshaw K, Smeeth K, Sheikh A. Topical treatments for seasonal allergic conjunctivitis: systematic review and meta-analysis of efficacy and effectiveness. $\mathrm{Br}$ J Gen Pract 2004;54:451-6.

[34] Sheikh A, Dhami S, Panesar HSJ. Clinical Evidence. In: Barton S, editor. London: BMJ Books, 2003;pp. 585-97.

[35] McHenry PM, Williams HC, Bingham EA. Management pf atopic eczema. Br Med J 2002;310:843-7.

[36] Sheikh A. Allergic problems. In: Khot A, Polemar A, editors. Practical general practice. 4th Ed Oxford: Butterworth Heneiman; 2003. p. 383-7.

[37] Project Team of The Resuscitation Council (UK). Update on the emergency medical treatment of anaphylactic reactions for first medical responders and for community nurses. Resuscitation 2001;48:241-3.

[38] Levy ML, Price D, Zheng X, Simpson C, Hannaford P, Sheikh A. Inadequacies in UK primary care allergy services: national survey of current provisions and perceptions of need. Clin Exp Allergy 2004;34:518-9.

[39] Department of Health. New Contractual Framework for Pharmacy. http://www.dh.gov.uk/PolicyAndGuidance/ MedicinesPharmacyAndlndustry/Prescriptions/Prescriptions Article/fs/en\%3FCONTENT_ID 4084524\&chk 46G2Ml. 2005.

[40] Blyth TP, Sundrum R. Adrenaline auto-injectors and schoolchildren: a community based study. Arch Dis Child 2002;86:26-7.

[41] Sheikh A, Khan-Wasti SS Price D, Smeeth L, Fletcher $M$, Walken 5iM. st d ctured allergy training for health professionals improves quality of life in patients with perennial rhinit's andomised controlled trial. J Allergy Clim 'minur. $200 \%, 115(2)$ :abs 168.

142] Poyal College of Physicians, Royal College of Pathologists. Good allergy practice - Standards of care for providers and purchasers of allergy services within the National Health Service. Clin Exp Allergy 1995;25:586-95.

[43] Royal College of Physicians. Allergy: the unmet need. A blueprint for better patient care. London: Royal College of Physicians; 2003.

[44] Department of Health. The NHS Plan. URL:http://www. dh.gov.uk/PublicationsAndStatistics/Publications/Annual Reports/DHAnnualReportsArticle/fs/en?CONTENT_ID=406[4827\&chk=3ReuSO]. 2005. 21-1-2005.

[45] House of Commons. Health- Sixth Report. http://www. publications.parliament.uk/pa/cm200304/cmselect/ cmhealth/696/69602.htm. 2005.

[46] Gruffydd-Jones K. A proposal for the process of accreditation by portfolio for a GPwSI in respiratory medicine. Primary Care Resp J 2004;14(1):13-20.

[47] Holmes S, Gruffydd-Jones K. A proposal for the annual appraisal of, and developmental support for, General Practitioners with a Special Interest (GPwSIs) in respiratory medicine. Primary Care Resp J 2005;14(3):161-5.

[48] Ewan PW, Durham SR. NHS Allergy Services in the UK: proposals to improve allergy care. Clin Med 2002;2(2):122-7.

Available online at www.sciencedirect.com science $(\mathcal{b}$ direct. 